\title{
PENGELOLAAN PEMBELAJARAN ILMU TAJWID MELALUI MEDIA AUDIO VISUAL
}

\author{
Hambali, Fathor Rozi, Nor Farida \\ Universitas Nurul Jadid, Kec. Paiton Kab. Probolinggo, Jawa Timur \\ Correspondence Email: fathorroziz3o@gmail.com
}

\begin{abstract}
Abstrak
This study aims to analyze and study the management of Tajweed learning through audio-visual media. This type of research is a method of qualitative case study type. The data collection techniques used in this study were observation, interview and documentation. Data analysis using display data, data reduction, and conclusions. The results showed the management of tajwid learning through audio-visual media at TPQ Al-Muhajirin through: selection of tajwid learning materials, audio-visual-based tajwid implementation design, group daily tests, independent daily tests and evaluations. The implication is that students are more eager to participate in tajwid learning and need training for teachers who have not mastered technology. The implication of using audio-visual media makes it easier for students and teachers in the implementation of tajwid science learning.
\end{abstract}

Keywords:

Tajweed Science, Learning, Audio Visual

\begin{abstract}
Penelitian ini bertujuan untuk menganalisa dan mengkaji pengelolaan pembelajaran tajwid melalui media audio visual. Jenis penelitian ini adalah metode kulitatif jenis study kasus. Teknik pengambilan data yang digunakan dalam penelitian ini adalah observasi, interview dan dokumentasi. Analisis data menggunakan data display, data reduction, dan kesimpulan. Hasil penelitian menunjukkan pengelolaan pembelajaran ilmu tajwid melalui media audio visual di TPQ Al-Muhajirin melalui : pemilihan materi pembelajaran tajwid, desain implimentasi tajwid berbasis audio visual, tes harian kelompok, tes harian mandiri dan evaluasi. Implikasi yang diperoleh siswa lebih bersemangat mengikuti pembelajaran tajwid dan butuh pelatihan bagi guru yang belum menguasai tekhnologi. Implikasi dari pengguna media audio visual memudahkan siswa dan guru dalam pelaksanaan pembelajaran ilmu tajwid.
\end{abstract}

Kata Kunci :

Ilmu Tajwid, Pembelajaran, Audio Visual

\section{PENDAHULUAN}

Al-Qurean mukjizat yang paling besar dari segala mukjizat yang pernah diberikan Allah Swt kepada seluruh Nabi dan Rasul-Nya karena al-Qurean bukan saja

untuk mematahkan segala bantahan dan argumen kaum musyrikin kepada kebenaran wahyu yang dibawah Rasulullah Muhammad Saw, tetapi ia juga ditujukan kepada seluruh umat manusia. Al-Qurean sebagai mukjizat terbesar Nabi Muhammad Saw, isinya tidak bertentangan dengan teknologi modern, bahkan mengungkapkan kebenaran al-Qurean. Di antara ayatayat al-Qurean yang mengungkapkan tentang masalah teknologi modern adalah:

Angin disebut al-Qureean, mengawinkan tumbuhtumbuhan dan lain-lain dalam QS. al-Hijr (15):22.

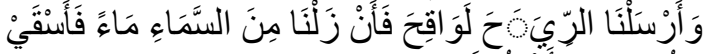

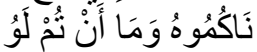

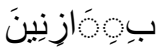

Artinya: "Dan Kami telah meniupkan angin untuk mengawinkan (tumbuhtumbuhan) dan Kami turunkan hujan dari langit, lalu Kami beri minum kamu 
dengan air itu, dan sekali-kali bukanlah kamu yang menyimpannya".(Yanggo, 2016)

Mengingat pentingnya peran $\mathrm{Al}-$ Qur'an bagi kehidupan manusia, maka pengenalan Al-Qur'an mutlak diperlukan. Upaya mengenalkan AlQur'an itu bukan

hanya mengetahui dari segi fisik dan aspek sejarah semata, namun yang lebih penting adalah bagaimana umat Islam mampu membaca sekaligus memahami makna terkandung dalam butir-butir ayat demi ayat dari AlQur'an.(Baharuddin, 2012)

Agar mampu membaca AlQur'an maka dibutuhkan yang namanya ilmu tajwid. Dengan ilmu tajwid maka anak mampu memahami bacaan Al-Qur'an dengan fasih dan benar. Agar mampu memahami bacaan Al-Qur'an yang baik dan benar maka diperlukan ilmu tajwid karena ilmu tajwid merupakan hal yang paling penting dalam memahami bacaan AlQur'an, dan masuk pada bagian materi ruang lingkup pembelajaran Al-Qur'an. Oleh sebab itu, pembelajaran tajwid diterapkan betujuan, pertama untuk meminimalisasi terjadinya kesalahan dalam membaca Al-Qur'an yang hal tersebut membawa kepada perubahan arti. Kedua adalah untuk membantu memahami Al- Qur'an dengan baik dan benar.(Prasmanita et al., 2020)

Mempelajari ilmu tajwid hukumnya fardu kifayah, jika sudah ada yang mempelajarinya maka kewajiban itu gugur untuk yang lainnya. Adapun mempraktikkan ilmu tajwid dalam membaca al-qur'an adalah fardu ain, yaitu kewajiban bagi setiap ummat islam dengan kata lain menggunakan ilmu tajwid merupakan keharusan. Maka barangsiapa yang tidak memperbaiki bacaan al-qur'annya maka dia berdosa.(Yullah, 2015) diakrenakan mempelajari tajwid hukumnya wajib maka dibutuhkan pengelolaan yang menyenangkan dalam pembelajaran tajwid.

Pengelolaan pembelajaran sangat dibutuhkan dalam rangka mengefektifkan pembelajaran (Rohmat, 2017). Keaktifan anak didik dalam pembelajaran yang sedang berlangsung, sangat diperlukan selama penerapan proses pembelajaran.(Afandi \& Zuraidah, 2020) Khususnya pada pembelajran tajwid, karena pembelajran tajwid memerlukan pemahaman yang dalam, perlu dihafalkan dan dihayati agar mudah dipahami oleh siswa yang mempelajarinya. Begitu pula dengan Pengelolaan kelas sangat dibutuhkan dalam upaya menciptakan dan mempertahankan kondisi kelas agar tetap kondusif dan efektif, sehingga proses belajar mengajar di kelas dapat berjalan dengan baik.(Fauzi et al., 2020)

Dengan menggunakan model pembelajaran diharapkan bisa memecahkan masalah siswa, sehingga dapat mengatasi permasalahan yang ada, hal ini juga diharapkan mampu menginspirasi siswa belajar lebih aktif, lebih giat dan antusias menikuti pembelajaran melalui indikator fungsional semua organ vital siswa yang dapat digunkan dalam memahami materi yang diberikan guru.(Partono et al., 2020)

Media pembelajaran sebagai sarana untuk meningkatkan kegiatan proses belajar mengajar. Media pembelajaran juga sangat berpengaruh terhadap hasil belajar siswa.(Kisma et al., 2020) Sedangkan media pembelajaran bisa difungsikan dalam menyampaikan informasi (materi pembelajaran) Itu bisa merangsang perhatian, minat, pikiran dan perasaan siswa mencapai tujuan pembelajaran 
dalam kegiatan pembelajaran. Fungsi utama media Belajar sebagai penyangga akan mempengaruhi iklim, kondisi dan Lingkungan belajar yang diciptakan oleh guru.(Atmaja, 2019). Fungsi utama media pembelajaran yaitu sebagai alat peraga akan mempengaruhi iklim, kondisi dan lingkungan belajar yang diciptakan oleh guru.(Rahmah \& Fa'atin, 2019)

Dalam proses berjalannya belajar mengajar, setiap guru selalu menginginkan anak didiknya dapat memperoleh hasil belajar yang optimal.(Nusroh \& Ahsani, 2020) Kenyataan dilapangan khususnya di TPQ Al-Muhajirin menunjukkan bahwa anak didik kurang minat dalam mengikuti pembelajaran tajwid, mereka cenderung malas-malasan bahkan bolos ketika pembelajaran tajwid. Pada umumnya penyelengaraannya pembelajaran tajwid difokuskan pada peningkatan kapasitas akademik berupa hafalan dalam memahami ilmu tajwid, yang prosesnya seringkali mengabaikan mood belajar anak yang berubah-ubah sehingga anak kurang berminat dan kurang tertarik dalam pembelajaran ilmu tajwid.

Untuk tercapainya nilai motivasi belajar dan hasil belajar yang baik, maka harus diciptakan lingkungan belajar yang memotivasi, menarik, membuat senang, hidup, kreatif dan tertantang sehingga siswa bersemangat untuk ikut pembelajaran di kelas itu.(Kisma et al., 2020) Pembelajaran konvensional kurang efektif penggunaanya dibandingkan dengan media. Media mampu menumbuhkan minat anak didik dalam penyerapan pembelajaran. Oleh sebab itu diperluka metode pembaharuan dalam penerapan pengelolaan ilmu tajwid agar siswa dapat lebih mudah memahami pembelajaran ilmu tajwid. Sejalan dengan lajunya zaman, ranah pendidikan tak luput dari tekhnologi yang bermunculan baik dari metode maupun cara pengaplikasian pembelajaran. Diantaranya media audio visual, rekam suara, maupun kaset digital. Berbagai produk teknologi ini membawa dampak bagi proses pembelajaran tajwid di lembaga pendidikan. Cara klasik biasanya diterapkan dengan cara yang monoton dan kurang memikat ketertarikan anak didik.

Ilmu dan teknologi berkembang pesat dari masa ke masa, salah satunya adalah teknologi informasi berbasis komputer yang dimanfaatkan oleh manusia dalam segala bidang seperti pendidikan.(Fajri, 2018) Dengan semakin maraknya sarana teknis di bidang pendidikan, dengan diterapkannya KBK (Kurikulum Berbasis Kompetensi) maka cara pembelajaran pengajian di beberapa institusi juga mengalami perubahan, hal ini semakin menambah semangat dan keaktifan anak didik dalam belajar. Salah satunya adalah penggunaan media audiovisual dalam pembelajaran Alquran. Penggunaan media audiovisual dalam proses pembelajaran dan pengajaran dapat membantu pendidik menginspirasi antusiasme peserta didik dalam menyimak pembelajaran. Penggunaan media audio visual menuntut siswa untuk tetap termotivasi dan merangsang semangat belajarnya agar lebih bergairah.(Fannani, 2009)

Menyajikan media sangat penting. Karena media dapat menunjang ketidak jelasan materi atau bahan yang disampaikan oleh guru, dengan adanya media materi akan lebih terarah dan jelas. Kompleksitas materi yang dapat diimplementasikan kepada siswa dapat terwujud disederhanakan 
dengan bantuan media.(Munthe, 2019) Media semacam ini dapat meningkatkan minat belajar siswa, karena siswa dapat mendengarkan audio dan menonton gambar..(Saputri \& Suryati, 2019)

Berdasarkan

pengamatan peneliti dilapangan pada beberapa tahun belakangan terdapat beberapa peneliti terdahulu yang dijadikan kajian awal oleh peneliti yang mempunyai relevansi terhadap pokok masalah yang akan diteliti. Adapun hasil dari penelitian yang dibuat perbandingan sebagai bentuk penelitian terlebih dahulu yaitu;

(Susilo Wirawan, Lalu Khairul Abdi, 2014) Mengatakan pengetahuan yang ada pada seseorang diterima melalui indera. Menurut penelitian para ahli, hal terpenting untuk mentransfer pengetahuan ke otak adalah penglihatan. Sekitar $75 \%$ hingga $87 \%$ pengetahuan manusia diperoleh melalui penglihatan, $13 \%$ diperoleh melalui pendengaran, dan $12 \%$ lainnya diperoleh melalui indera lain. Audiovisual adalah alat bantu yang paling cocok saat ini.

Kemudian (L. Aini, 2018) mengatakan audio visual merupakan seperangkat alat yang dapat memproyeksi gambar dan suara. Alatalat yang tergolong media audio visual contohnya televisi, video VCD, sound slide, dan film, Media audiovisual adalah kombinasi gambar dan suara yang saling mendukung, yang bisa mengunggah perasaan dan pikiran kepada orang yang menonton. Sehingga pembelajran dapat tersampaikan dengan cara menyenangkan jika menggunakan audio visual.

Selanjutnya (Khulasoh, 2017) menyampaikan bahwa tanpa disadari audio visual telah langsung merasuk ditengah-tengah kita sebagai suatu media yang sangat efektif untuk menyampaikan pesan dan informasi, untuk hiburan maupun dipergunakan dalam dunia pendidikan untuk pembelajaran.

Berangkat dari latar belakang tersebut, kami peneliti, berupaya untuk memfasilitasi upaya peningkatan mutu/kualitas pengelolaan pembelajaran tajwid melalui serangkaian kegiatan yang dikemas dalam satu paket program pemberdayaan dengan fokus masalah pengelolaan pembelajaran tajwid menggunakan audio visual di TPQ AlMuhajirin Paiton Probolinggo.

\section{METODE PENELITIAN}

Penelitian ini dilakukan pada TPQ Al-Muhajirin Paiton Probolinggo dengan menggunakan pendekatan kualitatif. TPQ Al-Muhajirin Paiton Probolinggo merupakan Pendidikan non formal dibawah naungan Yayasan pondok peantren mambaul ulum yang mencoba menerapkan pengelolaan pembelajaran ilmu tajwid melalui metode media audio visual.

Penelitian ini menggunakan pendekatan deskriptif kulitatif, sedangkan jenis penelitiannya menggunakan study kasus. Penelitin ini berusaha untuk mendeskripsikan gelaja, peristiwa, kejadian yang terjadi sekarang dimana penelitian ini akan memotret kejadian yang akan menjadi fokus penelitian kemudian akan dijabarkan sebagaimana adanya.(Anggraini \& Putri, 2019)

Informan dalam penelitian ini adalah kepala sekolah dan dewan guru. Untuk mendaapatkan gambaran tentang penerapan pengelolaan pembelajaran ilmu tajwid melalui metode media audio visual, peneliti menggunakan teknik observasi 
wawancara dan dokumen untuk mendapatkan data yang akurat tentang fokus penelitian sedang ditinjau. Analisi datanya dilakukan secara sirkuler, yang dimulai dari data display secara keseluruhan, dilanjutkan data reduction, yaitu pemilahan data yang telah terkumpul sesuai dengan tema yang telah ditentukan, dan diakhiri dengan penarikan kesimpulan penelitian, sebagai sebuah temuan penelitian.

\section{HASIL DAN PEMBAHASAN}

Metode pembelajaran yang inofatif sangat diperlukan dalam mengatasi kejenuhan serta dapat memotivasi atau meningkatkan antusias belajar anak didik. Hasil penelitian mengungkapkan bahwa, Pengelolaan Pembelajaran Ilmu Tajwid Melalui Metode Media Audio Visual di TPQ Al-Muhajirin Paiton Probolinggo melalui tahapan sebagai berikut ;

\section{PEMILIHAN BAHAN AJAR TAJID}

Bahan ajar atau isi pembelajaran yang akan disampaikan kepada siswa harus tepat sasaran, yaitu mempelajari materi pada waktunya pasti. Bahan ajar tersebut dapat berupa konsep, teori, dan rumus ilmiah. Cara, prosedur, dan langkah untuk melakukan sesuatu; dan norma, aturan, atau nilai.

$$
\text { Prinsip pemilihan materi }
$$

pembelajaran Tajwid meliputi: (a) prinsip yang relevan, (b) konsistensi dan (c) kecukupan. Pertama, prinsip relevansi berarti materi pembelajaran harus dikaitkan dengan standar kemampuan Tajwid dan realisasi kemampuan dasar. Kedua, prinsip konsistensi artinya secara konsisten siswa diajari materi tajwid yang sudah tersusun setelah benar-benar menguasai dilanjut kepada materi tajwid berikutnya. Ketiga, Prinsip kecukupan berarti bahwa materi yang diajarkan harus cukup untuk membantu siswa memahami isi materi pelajaran tajwid. Bahan materinya tidak boleh terlalu sedikit, dan tidak boleh terlalu banyak. Terlalu sedikit tidak akan membantu memenuhi standar kompetensi dan kemampuan dasar. Sebaliknya, terlalu banyak akan membuang waktu dan tenaga yang tidak perlu untuk mempelajarinya.

Hj. Khotimatul Husna Selaku kepala TPQ al-muhajirin menyampaikan pembelajaran tajwid yang diterapkan menggunakan bantuan media audio visual, dalam pemilihan materi pembelajaran tajwid di TPQ yang akan dijadikan audio visual dimulai dari pembelajaran tajwid paling dasar yaitu pengertian tajwid dan berlanjut pada materi hukum bacaan nun mati, hukum bacaan mim mati, hukum qolqolah, hukum bacaan alif lam, hukum membaca ra' dan hukum bacaan mad, Adapun video audio visual guru bisa download video dari chanel youtube maupun membuat video animasi sendiri.(Husna, 2021)

Nor Farida ustadzah TPQ almuhajirin juga mengatakan secara khusus guru mengklasifikasikan pembelajaran tajwid berbentuk audio secara berkala agar murid dapat lebih mudah memahami bahan ajar atau materi yang disampaikan oleh guru.(Farida, 2021)

\section{DESAIN IMPLIMENTASI TAJWID BERBASIS AUDIO VISUAL}

Salah satu tugas pendidik adalah menyediakan suasana belajar yang menyenangkan. Pendidik harus mencari cara untuk membuat pembelajaran menjadi menyenangkan dan mengesampingkan ancaman selama proses pembelajaran. (Septaningsih et al., 2020) Begitu pula 
yang dilakukan oleh para asatid TPQ Al-Muhajirin mengedepankan pembelajaran yang menarik dan menyenangkan.

Dinamika

pengembangan

metode membaca Al Qur'an harus terus digulirkan karena sejalan dengan perkembangan ilmu dan watak jaman.(Hariady, 2020) ustadzah sangat diharapkan berperan aktif dalam menentukan strategi/metode pembelajaran dikelas, karena metode yang sesuai akan mengantarkan kepada tujuan pendidikan yang diharapkan.(Kartikasari \& Mujib, 2020)

Untuk bisa membaca A-qur'an yang baik dan benar maka diperlukan ilmu tajwid dalam memahaminya. Dengan kata lain, pemahaman yang benar mengenai ilmu tajwid menjadi isi materi pembelajaran Al-Qur'an. Oleh sebab itu, pembelajaran tajwid diterapkan betujuan, pertama untuk meminimalisasi terjadinya kesalahan dalam membaca Al-Qur'an yang hal tersebut membawa kepada perubahan arti. Kedua adalah untuk membantu memahami Al- Qur'an dengan baik dan benar.

Dalam mengimplementasikan pembelajaran tajwid di TPQ AlMuhajirin guru menyampaikan menggunakan metode audio visual;

Pertama, menata tempat duduk siswa membentuk huruf (U), sehingga di mana-mana siswa bisa terlihat aktivitasnya oleh ustadzah secara keseluruhan.

Kedua, mengabsen kehadiran siswa dan diteruskan dengan menyampaikan tujuan pembelajaran dari materi tajwid yang akan dipelajari melalui audio visual kemudian ustadzah mengoprasikan media audio visual menggunakan perangkat laptop yang dihubungkan dengan proyektor dan kemudian dipertontonkan kepada siswa.

Ketiga, membacakan dan membahas tajwid dengan bacaan secara baik dan benar, kemudian guru menyampaikan hukum-hukumnya dan diteruskan dengan memberikan penjelasan tentang tajwid yang dibahas.

Keempat, diskusi bersama tentang tema tajwid yang dipelajari.

Metode pembelajaran ini diharapkan siswa akan lebih menyimak dan fokus dalam proses pembelajaran karena model pembelajaran audio visual adalah pembelajaran yang terdiri atas kegiatan mengamati, mendengar, menyimak dan melihat. Keberhasilan siswa tergantung pada seberapa baik guru menyampaikan materi dalam proses pembelajaran.

Peranan media dalam pembelajaran sangat penting bahkan sejajar dengan metode pembelajaran, karena metode tersebut biasanya digunakan dalam proses pembelajaran untuk mengintegrasikan media yang mana dapat menyesuaikan dengan kondisi yang dihadapi.(Syamsidar, 2019) Media audio visual juga mempunyai manfaat yang beragam diantaranya dengan menghadirkan media audio visual maka semua peserta didik dapat menikmati media tersebut sekaligus menyerap ilmu melalui media itu.(L. Aini, 2018)

Media audiovisual digunakan untuk meningkatkan hasil belajar siswa di TPQ Al-Muhajirin khususnya pada mata pelajaran tajwid. Semua guru ingin materi yang disampaikannya bisa diterima siswa dan berhasil membuat perubahan pada hasil belajar siswa. Tetapi terkadang itu semua tidak seperti yang guru inginkan, karena kesalahan bisa saja ada pada siswanya ataupun guru itu sendiri. 
Penggunaan

media pembelajaran dalam proses belajar mengajar mempunyai dua fungsi penting yaitu: (1) media sebagai alat bantu mengajar atau disebut sebagai dependent media karena posisi disini sebagai alat bantu (efektivitas), dan (2) media sebagai sumber belajar yang digunakan sendiri oleh peserta didik secara mandiri atau disebut dengan dependent media.(Zulkarnain, 2019)

Sebagaimana yang disampaikan oleh ustadzah alin nuhe selaku ustadzah tajwid pada tingkat al-ustha di TPQ Al-Muhajirin, beliau menyampaikan implementasi yang diberikan kepada siswa dengan berbantuan audiovisual yang diperoleh dari youtube maupun membuat video sendiri sangat berpengaruh terhadap daya minat bahkan kapaitas pencapaian lebih menonjol dari pada implementasi pembelajaran

secara

konvensional.(Nuhe, 2021)

Segenap ustad ustadzah TPQ AlMuhajirin melakukan perubahan pada media pembelajaran yang digunakannya supaya murid dapat menerima materi yang disampaikannya. Sebelumnya pembelajaran hanya dipaparkan dan dijelaskan secara konvensional. Namun hal ini dirasa kurang efektif dalam meningkatkan minat belajar anak, kemudian guru beralih kepada metode audio visual, secara kreatif guru mengaplikasikan video yang dibuat sendiri maupun video yang di download dari chanel youtube.

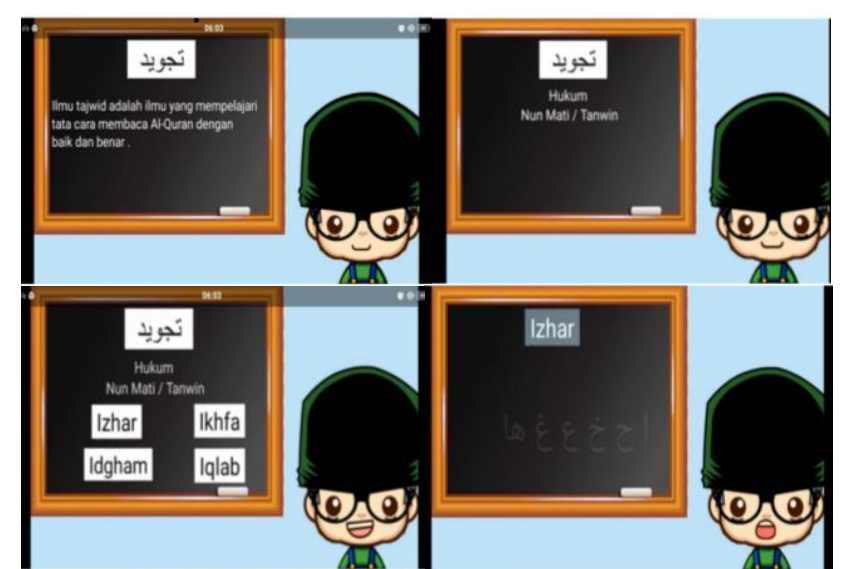

\section{Gambar 1. Implementasi Pembelajaran Tajwid}

\section{TES HARIAN KELOMPOK}

Tahap selanjutnya setelah melakukan pelaksanaan implementasi maka guru akan mengadakan tes kepada siswa secara berkelompok, siswa dibagi menjadi beberapa kelompok kemudian diberikan pertanyaan yang kemudian bisa di diskusikan dengan anggota kelomponya. Tes ini dilakukan untuk mengetahui sejauh mana tingkat pengetahuan siswa dalam menyerap pembelajaran yang mereka simak.

$$
\text { Ada banyak keuntungan }
$$
melakukan tes kelompok. Tes kelompok jauh lebih hemat waktu dalam banyak aspek. Karena, tes kelompok diberikan kepada banyak orang sekaligus. Tes berkelompok juga jauh lebih mudah untuk dinilai . Lebih banyak waktu diperlukan untuk menilai jawaban singkat atau pertanyaan. Pemberian skor juga lebih obyektif dan lebih dapat diandalkan karena subjektivitas pemberi nilai. Namun tes mandiri atau individu juga sangat diperlukan guna mengetahui kemampuan masingmasing siswa.

Ketika melakukan wawancara dengan ustadzah khairun nisa ustadzah di TPQ Al-Muhajirin, beliau menyampaikan tes kelompok dilakukan untuk memberikan semangat dalam menjawab pertanyaan-pertanyaan ustadzah sebelum melanjutkan pada 
tes mandiri atau individu, cara ini juga efektif dalam mengurangi rasa nervous atau rasa takut yang dihadapi siswa sebelum melanjutkan tes berikutnya.(Nisa, 2021)

\section{TES HARIAN MANDIRI}

Setelah melakukan tes kelompok maka akan dilanjutkan dengan melakukan tes mandiri atau individu yang dilakukan dengan cara;

Pertama, guru memanggil satu-satu siswa sesuaiabsensi.

Kedua, guru memberikan pertanyaan yang guru siapkan sesuai materi yang sudah dipelajari secara interview (face to face).

Ketiga, guru menilai sesuai hasil jawaban siswa kemudian dijadikan acuan untuk evaluasi selanjutnya

Dengan dilakukan tes setelah pelaksanaan implementasi maka mempermudah siswa dalam mengingat pembelajaran tajwid yang dipelajari, ustadzah juga bisa mengetahui pencapaian siswa melalui tes harian baik secara mandiri maupun kelompok, dengan begitu maka para ustadzah bisa melakukan pengulangan dibagian pembelajaran yang masih memerlukan pengulangan.(Latifah, 2021)

\section{EVALUASI}

Evaluasi adalah pengukuran dan peningkatan kegiatan, seperti membandingkan hasil kegiatan. Ini adalah proses pengumpulan, analisis, interpretasi, dan pengambilan keputusan Tentang perkembangan siswa dan data pembelajaran dalam kegiatan pembelajaran, atau Atur rencana layanan stimulus di institusi. Evaluasi bisa dikerjakan dalam berbagai hal, begitu pula dalam pembelajaran ilmu tajwid yang ada di TPQ mambaul ulum seperti; membuat catatan hasil pengamatan terhadap proses kegiatan, keaktifan dan kreativitas siswa.(Aliwar, 2016)

Dalam suatu pembelajaran tidak jauh dari yang namanya evaluasi. Dimana evaluasi itu untuk melihat pemahaman peserta didik selama proses pembelajaran. Hal ini disampaikan oleh Qurrotul aini selaku ustadzah TPQ Al-Muhajirin." evaluasi dilakukan dalam empat minggu sekali dalam menguji kemampuan siswa serta mengetahui tingkat pemahaman siswa terhadap ilmu tajwid.(Q. Aini, 2021)

Tujuan evaluasi adalah membuat rencana yang dikembangkan untuk mencapai tujuan yang ditentukan dan dilaksanakan. Hasil evaluasi dimaksudkan untuk direncanakan ulang dan digunakan sebagai administrasi dan pengelolaan akhir. Yaitu menggabungkan dan mengumpulkan data dengan tujuan standar.

Evalusi dilakukan selama satu bulan sekali dengan pemberian tugas essay atau pilihan ganda, evaluasi juga terkadang dilakukan dengan cara tanya jawab secara lisan tergantung ustadzah yang mendampingi. (Nisa, 2021)

Dalam setiap pembelajaran para ustadzah sudah mempersiapkan evaluasi untuk peserta didik. dengan terlaksananya evaluasi guru lebih tahu tujuan pembelajaran mana yang belum tercapai atau belum difahami oleh peserta didik dan belum sesuai dengan nilai KKM dalam pembelajaran tajwid dan keterampilan membaca $\mathrm{Al}$ Qureannya. Dengan melakukan evaluasi maka para ustadzah dapat mengukur kemampuan siswa lewat hasil kegitan yang dikerjakan.

\section{KESIMPULAN}

Berdasarkan pembahasan ini pengelolaan pembelajaran ilmu tajwid melalui metode media audio visual 
dapat ditarik kesimpulan sebagai berikut: para tenaga pengajar di TPQ Al-Muhajirin melakukan inovasi dan kreasi untuk mendesain pembelajaran tajwid agar lebih menarik dan menyenangkan pada anak melalui metode audio visual. Audio visual dapat meningkatkan ketertarikan dan antusias anak dalam mengikui pembelajaran tajwid khususnya pada anak TPQ Al-Muhajirin, tidak dapat digeneralisir untuk semua lembaga pendidikan. Hal ini sifatnya kasuistik dan sesuai dengan karakteristik pembelajar dan analisis lingkungan internal dan eksternal di lembaga tersebut. Implikasi dari pengguna media audio visual memudahkan siswa dan guru dalam pelaksanaan pembelajaran ilmu tajwid. Hal ini memberikan peluang kepada para peneliti selanjutnya, untuk mengkaji dan meneliti dengan kasus dan karakteristik yang berbeda.

\section{DAFTAR PUSTAKA}

Afandi, M., \& Zuraidah, Z. (2020). Kesiapan, Gaya Belajar dan Keaktifan Siswa Pada Pembelajaran Pendidikan Agama Islam di SMPN Bangkinang Kota. Belajea; Jurnal Pendidikan Islam, 5(2), 221.

Aini, L. (2018). Implementasi Media Audio Visual Dalam Meningkatkan Hasil Belajar Pendidikan Agama Islam Anak Tunarungu Di Sekolah Luar Biasa Pkk Provinsi Lampung. Aini, Q. (2021). Interview.

Aliwar. (2016). Penguatan Model Pembelajaran Baca Tulis Quran Dan Manajemen Pengelolaan Organisasi (Tpa). Jurnal Al-Ta'dib, 9(1), 21-37.

Anggraini, W., \& Putri, A. D. (2019). Penerapan Metode Bermain Peran (Role Playing) dalam
Mengembangkan Kognitif Anak Usia 5-6 Tahun. JECED : Journal of Early Childhood Education and Development, 1(2), 104-114.

Atmaja, H. T. (2019). Pelatihan dan Pendampingan Pembuatan dan Pemanfaatan Media Audio-Visual Interaktif dalam Pembelajaran Sejarah yang Berbasis pada Konservasi Kearifan Lokal Bagi MGMP Sejarah Kabupaten Banjarnegara. JURNAL PANJAR, 1(2), 131-140.

Baharuddin. (2012). Metode pembelajaran ilmu tajwid dalam meningkatkan kemampuan membaca al-qur'an Santri pondok pesantren tahfizh al-qur'an alimam 'ashim makassar.

Fajri, N. (2018). Implementasi aplikasi media pembelajaran belajar tajwid menggunakan.

Fannani, A. Z. (2009). Pemanfaatan Media Audio Visual Dalam Pembelajaran Alqur'an Di Ma'had Umar Bin Khattab Surabaya.

Farida, N. (2021). Interview.

Fauzi, A., Helnanelis, H., \& Fahmi, A. (2020). Pengaruh Pengelolaan Kelas Terhadap Motivasi Belajar Siswa Pada Mata Pelajaran Fiqih (Studi di MTs Al-Fitroh Tangerang). Belajea; Jurnal Pendidikan Islam, 5(1), 51.

Hariady, B. S. dan B. (2020). Pengembangan Pembelajaran Membaca Al Qur'an Tingkat Dasar Berdasarkan Ilmu Tajwid Dengan Metode Joyful Learning. Lintang Songo: Jurnal Pendidikan, 3(1), 698 o.

Husna, H. K. (2021). Interview.

Kartikasari, D., \& Mujib, Z. (2020). Hambatan Pengimplementasian Kurikulum 2013 Pada Proses Pembelajaran Universalime Islam (PAI). Belajea; Jurnal Pendidikan 
Islam, 5(2), 181.

Khulasoh. (2017). Meningkatkan Keterampilan Menulis Puisi Menggunakan Media Audio Visual Pokok Bahasan Melengkapi Puisi Anak. Jurnal Dinamika Pendidikan Dasar Volume, 9(1), 13-22.

Kisma, A. D., Fakhriyah, F., \& Purbasari, I. (2020). Penggunaan Media Pembelajaran Diorama untuk Meningkatkan Pemahaman Konsep Kelas IV SD Negeri 2 Hadipolo. NATURALISTIC: Jurnal Kajian Penelitian Pendidikan Dan Pembelajaran, 5(1), 635-642.

Latifah. (2021). Interview.

Munthe, K. B. (2019). Efektivitas penggunaan media audiovisual dalam Meningkatkan hasil belajar siswa pada materi tajwid di smp swasta galih agung pesantren darul arafah raya Medan.

Nisa, K. (2021). Interview.

Nuhe, A. (2021). Interview.

Nusroh, S., \& Ahsani, E. L. F. (2020). Analisis Kesulitan Belajar Pendidikan Agama Islam (PAI) Serta Cara Mengatasinya. BELAJEA: Jurnal Pendidikan Islam, 5(1).

Partono, P., Hamengkubuwono, H., \& Fransiska, J. (2020). Model Example Non Example Dalam Pembelajaran Tajwid. Belajea; Jurnal Pendidikan Islam, 5(1), 23.

Prasmanita, D., Khamid, A., Zamroni, A., \& Nasitoh, O. E. (2020). Implementasi Pembelajaran Tajwid dan Ketrampilan Membaca Al-Qur'an dalam Materi Al-Qur'an Hadist. Attractive: Innovative Education Journal, 2(2), 45-53.

Rahmah, F. N., \& Fa'atin, S. (2019). Pengembangan Kualitas Media Pembelajaran Tajwid Di $\mathrm{Mi} \mathrm{Nu}$ Raudlatul Wildan Desa Ngembalrejo Kudus. Quality, 7(1),
29-49.

Rohmat. (2017). Manajemen Pendidikan anak usia dini. YIN YANG, 12(2), 300-325.

Saputri, A. A., \& Suryati, S. (2019). Pengaruh Pendidikan Kesehatan Menggunakan Audio-Visual Terhadap Pengetahuan Cuci Tangan Pakai Sabun (Ctps) Pada Anak Kelas Iv Di Mi Jamilurrahman Bantul. Medika Respati: Jurnal Ilmiah Kesehatan, 14(3), 245-244.

Septaningsih, U., Fathurohman, I., \& Setiawan, D. (2020). Keterampilan Guru Melalui Model Picture and Picture Berbantuan Media Roda Putar Kelas IV SDN Wonorejo 2 Demak. NATURALISTIC: Jurnal Kajian Penelitian Pendidikan Dan Pembelajaran, 5(1), 661-666.

Susilo Wirawan, Lalu Khairul Abdi, N. K. S. S. (2014). Penyuluhan Dengan Media Audio Visual Dan Konvensional Ter- Hadap Pengetahuan Ibu Anak Balita. Jurnal Kesehatan Masyarakat, 10(1), 8o-87.

Syamsidar. (2019). Keunggulan Media Audiovisual dalam Pembelajaran Al-Quran Hadis di MAN 1 Bone. Al-Qayyimah, 2(1), 43-59.

Yanggo, H. T. (2016). Al-Qur'an Sebagai Mukjizat Terbesar. Waratsah, o1(02), 1-26.

Yullah, R. (2015). Metode Pembelajaran Tajwid Didayah Jabar Nur Kecamatan Dewantara Kabupaen Aceh Utara. JurnalIlmiah DIDAKTIKA, 15(2), 244-265.

Zulkarnain, F. (2019). Pengembangan Media Pembelajaran Magic Disc Tajwid Pada Pelajaran Qur'an Hadist Materi Nun Mati (Sukun) Atau Tanwin Mts Negeri 1 Lampung Tengah.

ukamaju 1. Tanggal 21 Juni 2017. 